EM

\title{
ANÁLISE DA FRAGILIDADE AMBIENTAL POTENCIAL E EMERGENTE DA BACIA HIDROGRÁFICA DO CÓRREGO DA ONÇA EM PRESIDENTE PRUDENTE / SP
}

\section{ANALYSIS OF THE POTENTIAL AND EMERGING ENVIRONMENTAL FRAGILITY OF THE ONÇA STREAM HYDROGRAPHIC BASIN IN PRESIDENTE PRUDENTE / SP}

\author{
Edmiler José Silva DEGRANDE ${ }^{1}$ \\ Leandro Neri BORTOLUZZI ${ }^{2}$
}

\begin{abstract}
Resumo: Nas últimas décadas a importância dada aos estudos ambientais tem sido notória, visto que as relações sociedade-natureza têm se mostrado cada vez mais adversas. No âmbito da geomorfologia, tais trabalhos têm como limiar principal a Teoria Geral dos Sistemas como base teórico-metodológica para seus estudos, visando a análise holística dos aspectos ambientais e a inserção do agente antrópico como modificador dos sistemas naturais. Partindo deste pressuposto, este trabalho busca analisar as fragilidades ambientais potencial e emergente da bacia hidrográfica do córrego da Onça, localizada no município de Presidente Prudente- SP, considerando a metodologia de Fragilidade Ambiental proposta por Ross (1994), com vista à contribuição para o planejamento ambiental desta área. Para a realização do trabalho utilizou-se os softwares ArcGis 10.4, para a confecção dos mapas de Fragilidade Ambiental Potencial e Emergente da bacia. Os resultados apontam a predominância de índices de instabilidade ambiental média tanto no tocante a Fragilidade potencial quanto a Fragilidade emergente, somando percentuais de 41,4 \% 68,3\%, respectivamente. Dessa forma a aplicação da metodologia de Fragilidade ambiental se mostra como uma importante ferramenta para o planejamento ambiental das áreas rurais e urbanas da bacia aqui apresentada.
\end{abstract}

Palavras-Chave: Fragilidade ambiental; Análise sistêmica; Planejamento ambiental.

\begin{abstract}
In recent decades the importance given to environmental studies has been notorious, since society-nature relations have been increasingly adverse. In the scope of geomorphology, such works have as main threshold the General Theory of Systems as a theoretical-methodological basis for their studies, aiming at the holistic analysis of the environmental aspects and the insertion of the anthropic agent as modifier of the natural systems. Based on this assumption, this work seeks to analyze the potential and emerging environmental fragilities of the Jaguar stream water catchment area, located in the municipality of Presidente Prudente-SP, considering the Environmental Fragility methodology proposed by Ross (1994), with a view to contributing to the environmental planning of this area. In order to carry out the work, the software ArcGis 10.4 was used to make the maps of Potential and Emergent Environmental Fragility of the basin. The results indicate the predominance of indices of environmental instability, both in terms of potential Fragility and Emergent Fragility, representing a percentage of $41.4 \%, 68.3 \%$, respectively. In this way the application of the Environmental Fragility methodology is shown as an important tool for the environmental planning of the rural and urban areas of the basin presented here.
\end{abstract}

Keywords: Environmental fragility; Systemic analysis; Environmental planning.

\footnotetext{
${ }^{1}$ Doutorando em Geografia pela FCT Unesp/Presidente Prudente. E-mail: edmiler.js@hotmail.com - Bolsista CNPQ.

${ }^{2}$ Doutorando em Geografia pela FCT Unesp/Presidente Prudente. E-mail: bortoluzzi_@hotmail.com - Bolsista CAPES.
} 
EM

\section{Introdução}

A necessidade de estudos sobre as dinâmicas naturais tem se mostrado substancial na atualidade visto que a relação sociedade-natureza apresenta-se de modo deletério, sendo imprescindível a busca pelo desenvolvimento de métodos eficazes para o planejamento ambiental e a mitigação de impactos ambientais negativos. Dentro desta perspectiva a Teoria Geral dos Sistemas tem demonstrado grande contribuição às pesquisas de cunho ambiental, partindo de uma análise sistêmica do meio e a inserção do homem como um dos agentes modificadores da paisagem.

No que tange à ciência geomorfológica, Strahler (1952) se destaca como um dos precursores em estudos partindo de uma abordagem dinâmica dos processos geomorfológicos, defendendo a concepção de sistemas abertos, que por sua vez, é reiterado com a teoria de Equilíbrio Dinâmico de Hack (1960). Neste viés teórico-metodológico, Tricart (1977) propõe o conceito de Ecodinâmica, tendo em vista o equilíbrio dinâmico pela troca de energia e matéria na natureza, todavia, o autor também salienta o desequilíbrio temporário ou permanente deste processo, resultante da ação humana.

De acordo com o conceito de Unidades Ecodinâmicas de Tricart (1977), a qualidade do meio ambiente pode ser classificada em níveis, a saber: Meios Estáveis, Meios Intergrades e Meio Fortemente Instáveis. Sendo o primeiro nível caracterizado pela não intervenção antrópica e os demais pela média e intensa interferência humana no sistema natural, respectivamente.

Fundamentado no conceito de Unidades Ecodinâmicas de Tricart (1977), Ross (1994) propõe os termos Unidades Ecodinâmicas Instáveis ou de Instabilidade Emergente - áreas intensamente alteradas pela ação antrópica - e Unidades Ecodinâmicas Estáveis ou de Instabilidade Potencial - áreas que se encontram em maior equilíbrio dinâmico. Tal proposição é utilizada pelo referido autor para classificar o grau de fragilidade ambiental de determinas áreas, as quais podem apresentar níveis de instabilidade que variam de muito fraca à muito forte.

As características do relevo (declividade e curvatura), o clima (com ênfase na pluviosidade), tipos de solos e a cobertura e uso da terra são variáveis analisadas nos estudos de fragilidade ambiental, portanto, o estudo integrado desses elementos é essencial para a compreensão da realidade ambiental da área estudada, sendo um instrumento importante para o planejamento ambiental e estratégico. Nesse sentido, Spörl e Ross (2004, p. 40) afirmam que:

Estes estudos relativos às fragilidades dos ambientes são de extrema importância ao Planejamento Ambiental. A identificação dos ambientes naturais e suas fragilidades potenciais e emergentes proporcionam uma melhor definição das diretrizes e ações a serem implementadas no espaço físico-territorial, servindo de base para o zoneamento e fornecendo subsídios à gestão do território.

Portanto, o planejamento ambiental pode ser caracterizado como ações que visam o melhoramento do meio ambiente e que tem como repercussão a melhoria da qualidade da vida humana (GALLOPIN, 1981 apud BOTELHO 2005). Para tanto, conforme Cendrero (1982) apud Botelho (2005), esta atividade deve ter o caráter intelectual e holístico, abarcando aspectos físico-naturais, sociológicos, políticos e econômica de determinada área.

Dessa forma este trabalho visa analisar a Fragilidade Ambiental Potencial e Emergente na bacia hidrográfica do córrego da Onça em Presidente Prudente- SP. A pesquisa justifica-se diante da importância empregada as técnicas para o planejamento ambiental em bacias 
EM

QUESTÃO

V.13 N. $03 \bullet 2020$

pág. 33-50

hidrográficas, utilizando-se da metodologia de Fragilidades ambientais como principal subsídio na obtenção de dados sobre a qualidade ambiental da referida bacia, assim como para o planejamento ambiental da área em questão para instituições públicas, privadas, e como respaldo para outras pesquisas.

\section{Localização e caracterização da área de estudo}

A bacia hidrográfica do córrego da Onça possui uma área aproximada de $118 \mathrm{Km}^{2} \mathrm{e}$ está inserida no município de Presidente Prudente - São Paulo, como pode ser observado na Figura 1, sendo constituinte de redes hidrográficas com grande importância regional e nacional, como as bacias hidrográficas do rio do Peixe e Paraná, respectivamente.

Figura 1 - Localização da bacia hidrográfica do córrego da Onça.

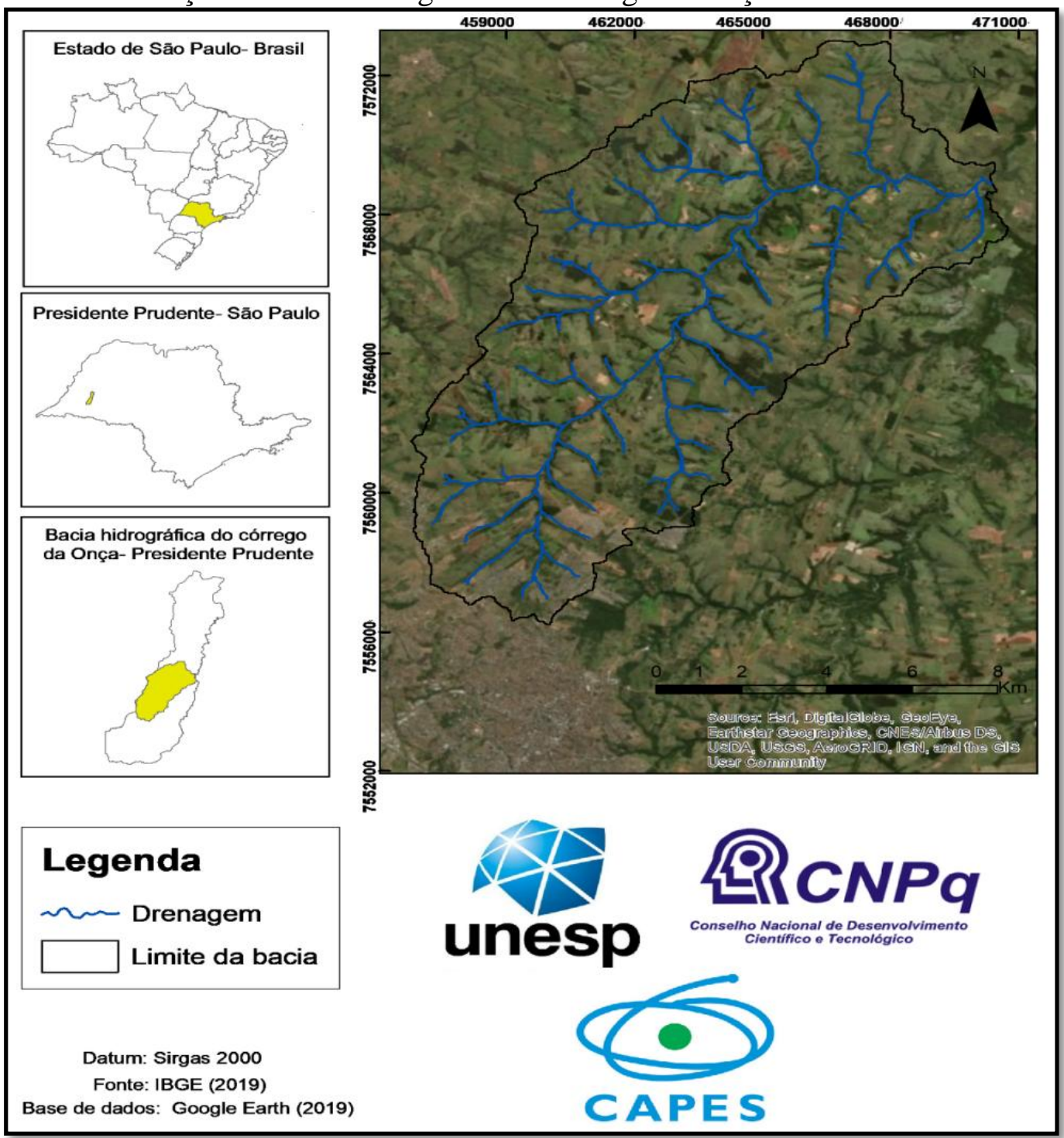

Org: Os autores (2019).

Monteiro (1973), ao caracterizar os tipos climáticos predominantes no município de Presidente Prudente destaca a interferência de sistemas polares durante o inverno, havendo neste a atuação de um clima frio e seco, e ainda a influência de sistemas climáticos tropicais 
EM

QUESTÃO

V.13 N. $03 \bullet 2020$

pág. 33-50

durante o verão, repercutindo no predomínio de clima quente e úmido neste período. No que tange as taxas pluviométricas médias, estas variam entre 1200 a $1500 \mathrm{~mm}$, e a temperatura média anual acima de $22^{\circ} \mathrm{C}$ (BOIN, 2000).

Considerando seus aspectos geomorfológicos, Presidente Prudente está sobre a morfoestrutura da Bacia Sedimentar do Paraná e na morfoescultura do Planalto Ocidental Paulista, constituída principalmente por arenitos do grupo Bauru (ROSS e MOROZ, 1996). Seus dados morfométricos revelam altitudes entre 300 e 600 metros e classes de declividade que se concentram entre os percentuais de 10 a 20\% (NUNES et al. 2006). Especificamente na área do objeto de estudo, a altimetria do relevo está entre 325 e 486 m, enquanto os dados de declividade apresentam classes que variam entre 0 a 34\%, predominando áreas com índices entre 12 a $20 \%$ (Figuras 2 e 3).

Figura 2 - Hipsometria da bacia hidrográfica do córrego da Onça.

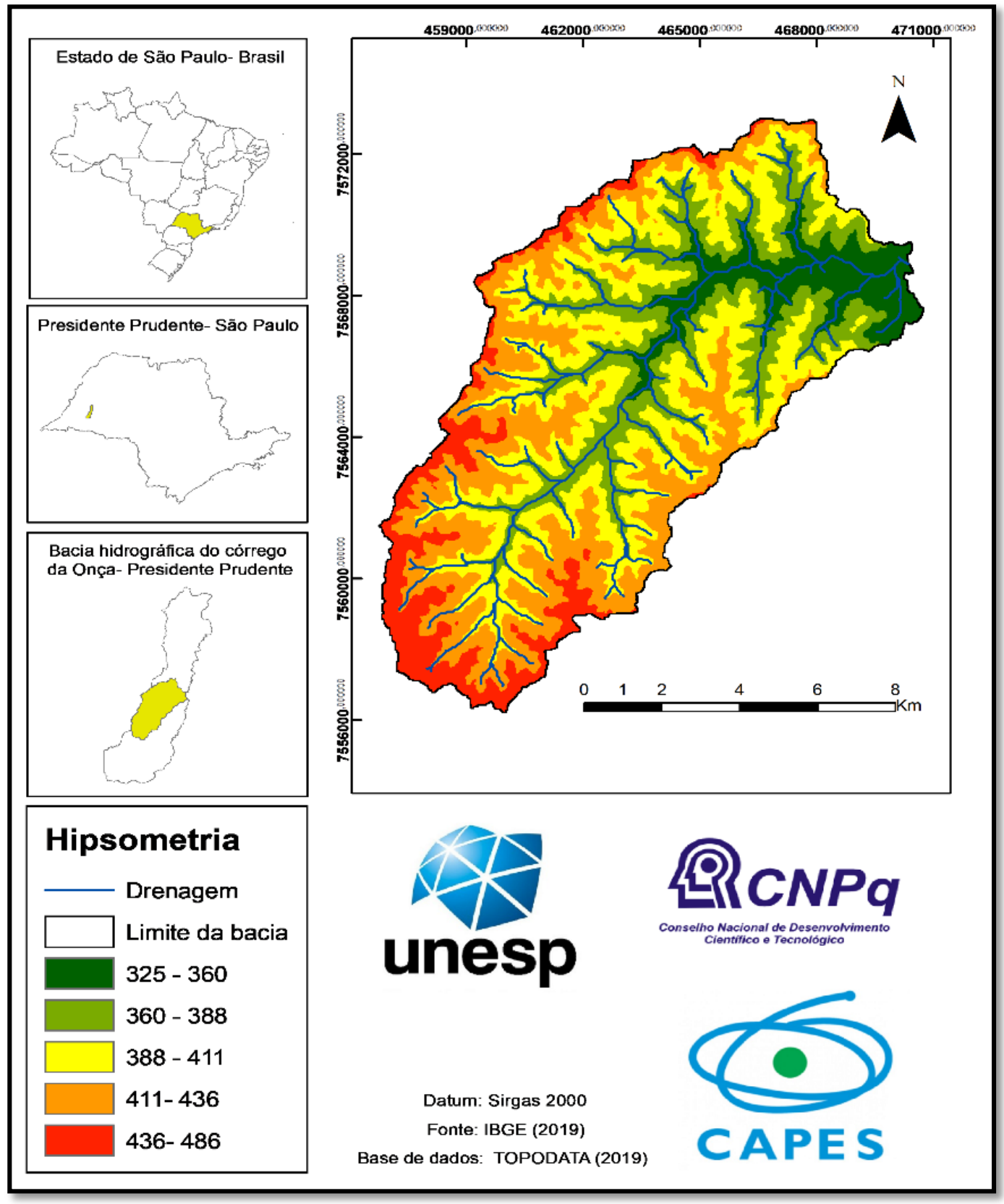

Org: Os autores (2019). 
EM

Figura 3 - Classes de declividade da bacia hidrográfica do córrego da Onça.

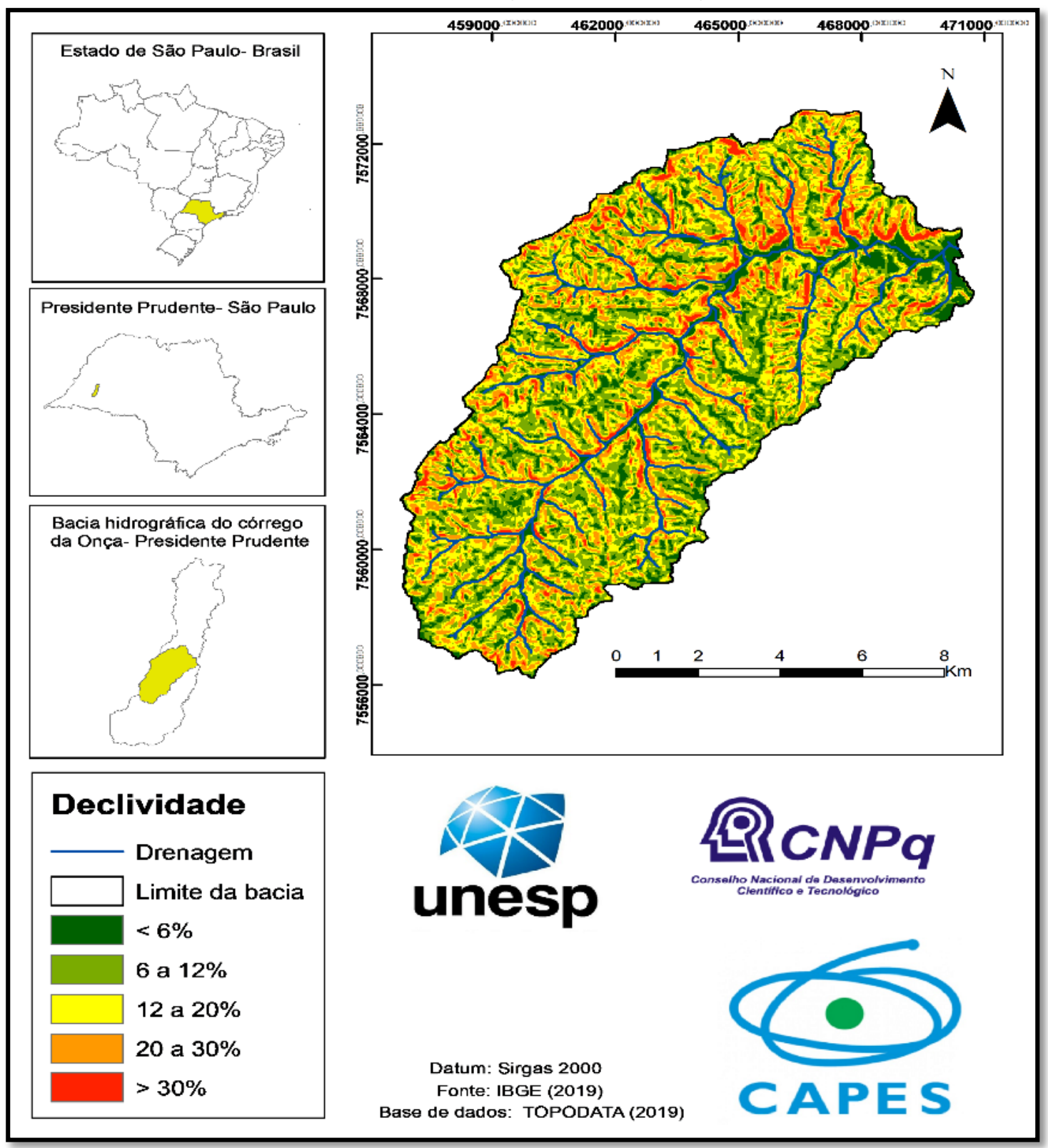

Org: Os autores (2019).

No que concerne as características da curvatura do relevo de Presidente Prudente (Figura 4), Nunes et al (2008) destacam o domínio das vertentes convexo-côncavas e retilíneas, as quais podem estar associadas a depósitos coluvionares ou afloramentos da Formação Adamantina.

Outros compartimentos geomorfológicos identificados no município por Nunes et al (2008) foram os Alvéolos e Planícies aluviais, e ainda, colinas convexizadas com topos suavemente ondulados, porém, em alguns setores denota-se topos mais aguçados resultantes de afloramentos característicos da Formação Adamantina.

Dessa forma, Godoy (1999, p. 19) caracteriza litológicamente a Formação Adamantina: 
EM

[...] pela ocorrência de bancos de arenito de granulação fina a muito fina, de cor rósea a castanho, com espessuras variáveis entre 2 e 20 metros e alternados com lamitos, siltitos e arenitos lamíticos, de cor castanha avermelhada a cinza castanho. Quanto à estrutura, as estratificações cruzadas são próprias dos estratos mais areníticos, ao passo que, nos termos lamíticos subordinados a eles, são mais comuns os bancos maciços ou dispostos em acamamento plano-paralelo, com a presença frequiente de marcas de ondas e microestratificação cruzada.

Sendo assim, Almeida et al (1981 apud Godoy, 1999) ao analisar as características da Formação Adamantina e sua influência sobre as formas de relevo, reitera a ocorrência de relevos com índices de ondulação mais aguçados a concentração de bancos areníticos compactados.

Figura 4 - Curvatura do relevo da bacia hidrográfica do córrego da Onça.

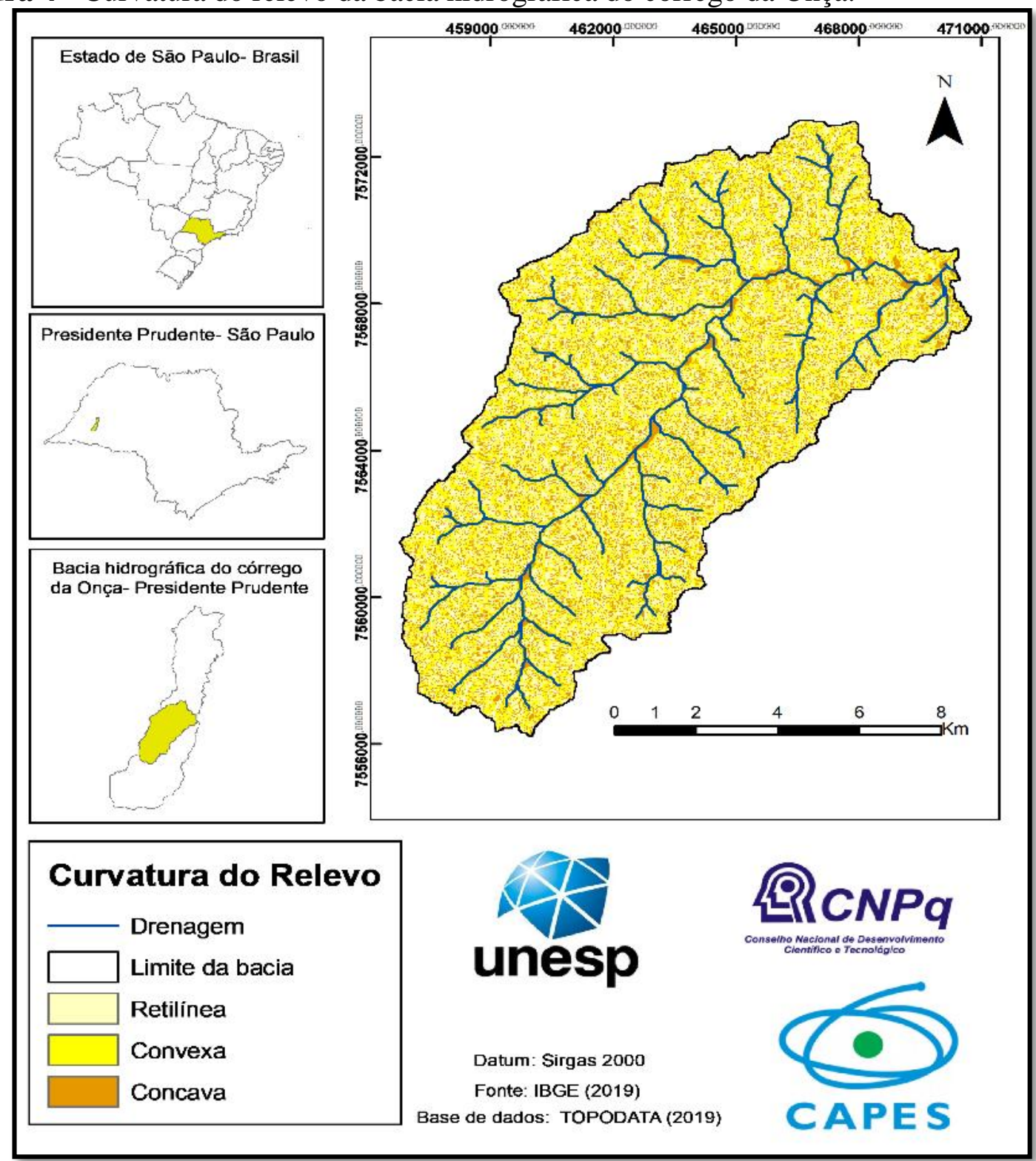

Org: Os autores (2019). 
EM

No que atine aos tipos de solos, o levantamento pedológico realizado por Fushimi (2012) para o município de Presidente Prudente, permitiu que fossem identificadas na bacia do córrego da Onça as seguintes classes: Solos Desenvolvidos (associação de Latossolos Vermelhos), Solos Rasos a Desenvolvidos (associação de Argissolos Vermelhos), Solos Rasos (associação de Neossolos Rigolíticos) e Solos Hidromórficos (associação de Planossolos e Gleissolos), Figura 5.

Figura 5 - Tipos de solos da bacia hidrográfica do córrego da Onça.

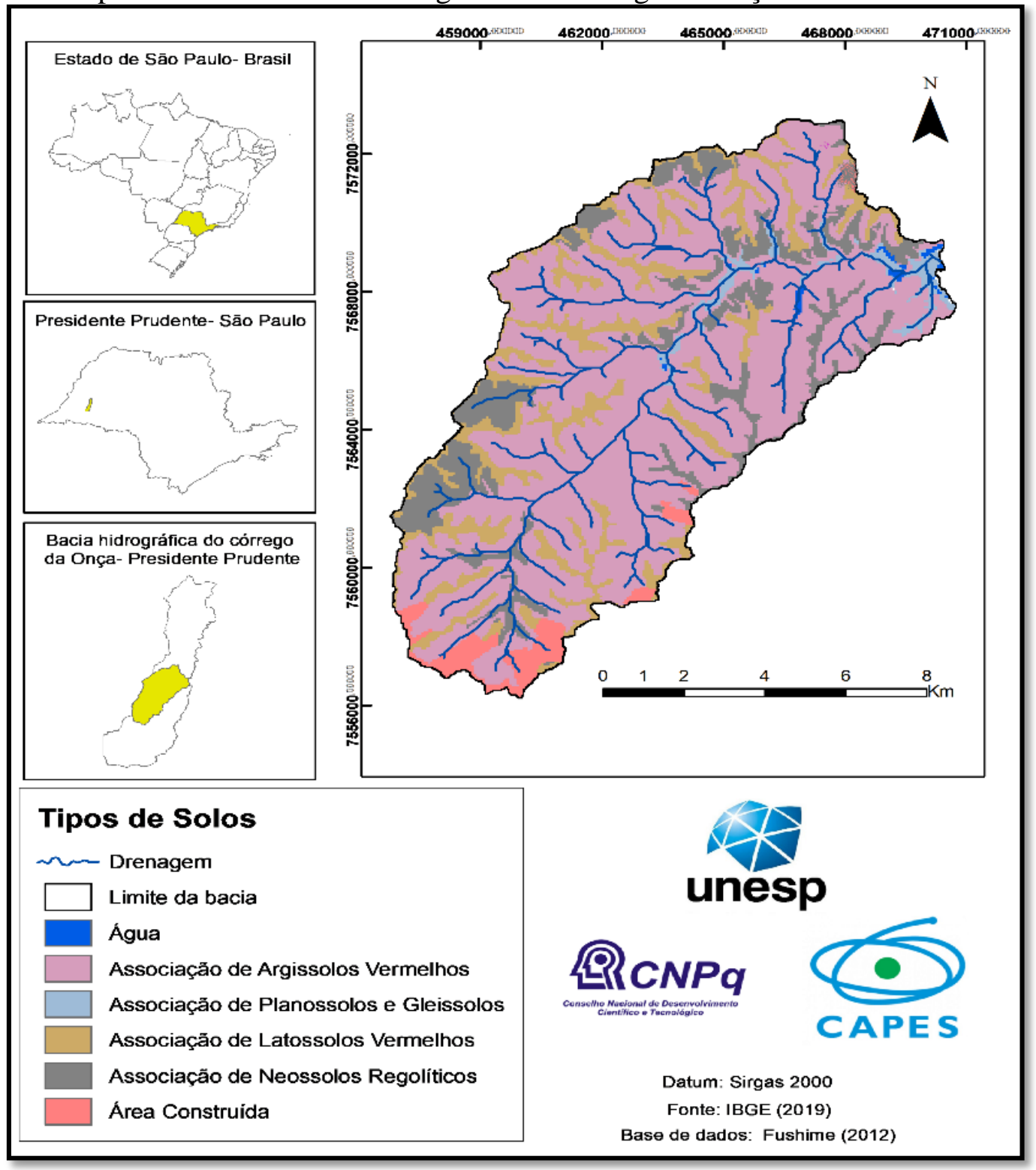

Org: Os autores (2019).

Originalmente, a área que compreende o município de Presidente Prudente era coberta por uma densa Floresta Estacional Semidecidual. No entanto a ocupação humana nesta área, impulsionada pelo avanço preliminar da cultura cafeeira, deu origem a outros usos da terra, como núcleos urbanos que se expandiram resultando na atual área urbana de Presidente Prudente, e ainda, algodão, amendoim, e mais recentemente, cana de açúcar e pastagem. (GODOY, 1999). Na área que abarca a bacia aqui estudada a malha urbana se apresenta 
EM

ínfima, sendo seu perímetro majoritariamente utilizado por culturas herbáceas arbustivas, seguida de solo exposto e cobertura arbórea (Figura 6).

Figura 6 - Cobertura vegetal e uso da terra na bacia hidrográfica do córrego da Onça.

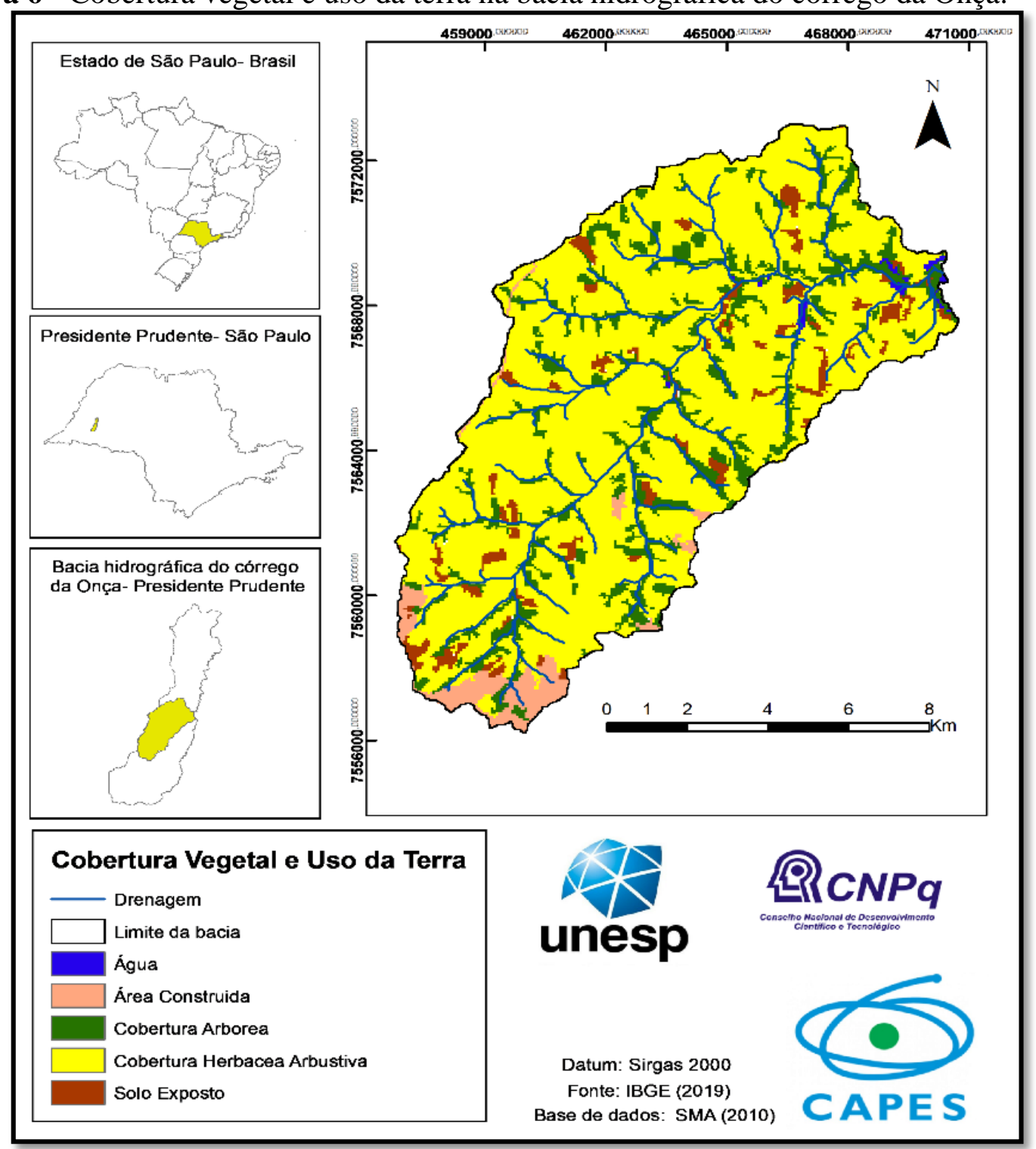

Org: Os autores (2019).

\section{Aplicação da metodologia de Fragilidade ambiental}

A metodologia utilizada neste trabalho parte da análise integrada dos aspectos naturais e sociais da área estudada, visando à compreensão dos níveis de fragilidade ambiental presente na mesma. Sendo assim esta pesquisa se pautou nos pressupostos teóricosmetodológicos de Ross (1994), que, com base no conceito de Ecodinâmica proposto por Tricart (1977) tem introduzido nas análises ambientais o conceito de Fragilidade ambiental.

Segundo Ross (1994) para os estudos de fragilidade ambiental é imprescindível o levantamento básico de geomorfologia, tipos de solos, cobertura vegetal/uso da terra e clima da paisagem, sendo a análise sistêmica desses elementos um método consistente para o diagnóstico ambiental. Dessa forma, cada componente da paisagem pode apresentar níveis de 
EM

QUESTÃO

$\mathrm{V} .13 \bullet \mathrm{N} .03 \bullet 2020$

pág. 33-50

fragilidade ambiental diferentes, divididos em cinco classes: 1 - Muito Fraca, 2 - Fraca, 3 Média, 4 - Forte e 5 - Muito Forte; portanto, as variáveis mais estáveis são aquelas que apresentam valores mais próximos de 1; as intermediárias em torno de 3 e as mais instáveis, as mais próximas de 5 (Quadro 1).

Quadro 1 - Índices de Fragilidade Ambiental* considerando os aspectos geomorfológicos, tipos de solos, cobertura vegetal/uso da terra e clima.

\begin{tabular}{|c|c|c|c|c|}
\hline Declividade $^{\text {a }}$ & $\underset{b}{\text { Vertentes }}$ & Tipos de Solos $^{a}$ & $\begin{array}{c}\text { Cobertura e uso da } \\
\text { terra }^{\text {a }}\end{array}$ & Características pluviométricas \\
\hline até $6 \%$ & - & $\begin{array}{l}\text { Latossolo roxo, } \\
\text { Latossolo } \\
\text { Vermelho } \\
\text { escuro } \\
\text { Vermelho } \\
\text { textura argilosa. }\end{array}$ & $\begin{array}{l}\text { Florestas, matas ciliares, } \\
\text { florestas cultivadas com } \\
\text { biodiversidade. }\end{array}$ & $\begin{array}{l}\text { Situação pluviométrica com } \\
\text { distribuição regular ao longo do } \\
\text { ano, com volumes anuais não } \\
\text { muito superiores a } 1000 \mathrm{~mm} / \\
\text { ano. }\end{array}$ \\
\hline de 6 a $12 \%$ & - & $\begin{array}{l}\text { Latossolo } \\
\text { Amarelo } \\
\text { Vermelho- } \\
\text { amarelo textura } \\
\text { média/ argilosa }\end{array}$ & $\begin{array}{lr}\text { Cultivo de ciclo longo } \\
\text { em curvas de nível/ } \\
\text { terraceamento } & \text { como } \\
\text { café, laranja } & \text { com } \\
\text { forrageiras entre ruas, } \\
\text { pastagens com baixo } \\
\text { pisoteio, silvicultura de } \\
\text { eucalipto com sub- } \\
\text { bosque de nativas. }\end{array}$ & $\begin{array}{l}\text { Situação pluviométrica com } \\
\text { distribuição regular ao longo do } \\
\text { ano, com volumes anuais não } \\
\text { muito superiores a } 2000 \mathrm{~mm} / \\
\text { ano. }\end{array}$ \\
\hline de 12 a $20 \%$ & Retilínea & $\begin{array}{l}\text { Latossolo } \\
\text { Vermelho- } \\
\text { amarelo textura } \\
\text { média/argilosa. }\end{array}$ & $\begin{array}{lr}\text { Cultivo de ciclo longo } \\
\text { em curvas de nível/ } \\
\text { terraceamento } & \text { como } \\
\text { café, laranja } & \text { com } \\
\text { forrageiras entre ruas, } \\
\text { pastagens com baixo } \\
\text { pisoteio, silvicultura de } \\
\text { eucalipto com sub- } \\
\text { bosque de nativas. }\end{array}$ & $\begin{array}{l}\text { Situação pluviométrica com } \\
\text { distribuição anual desigual, com } \\
\text { períodos secos entre } 2 \text { e } 3 \text { meses } \\
\text { no inverno, e no verão com } \\
\text { maiores intensidades } \\
\text { dezembro a março. }\end{array}$ \\
\hline de 20 a $30 \%$ & Convexa & $\begin{array}{l}\text { Podzóico } \\
\text { Vermelho- } \\
\text { amarelo textura } \\
\text { média/arenosa, } \\
\text { Cambissolos. }\end{array}$ & $\begin{array}{l}\text { Culturas com ciclo longo } \\
\text { de baixa densidade (café, } \\
\text { pimenta do reino, laranja } \\
\text { com solo exposto entre } \\
\text { ruas), culturas de ciclo } \\
\text { curto (arroz, feijão soja } \\
\text { milho algodão com } \\
\text { cultivo em curvas de } \\
\text { nível/ terraceamento). }\end{array}$ & $\begin{array}{l}\text { Situação pluviométrica com } \\
\text { distribuição anual desigual, com } \\
\text { período seco entre } 3 \text { e } 6 \text { meses, } \\
\text { alta concentração das chuvas no } \\
\text { verão entre novembro e abril, } \\
\text { quando ocorrem de } 70 \text { a } 80 \% \text { do } \\
\text { total das chuvas. }\end{array}$ \\
\hline $\begin{array}{c}\text { acima de } \\
30 \%\end{array}$ & Côncava & $\begin{array}{l}\text { Podzolizados } \\
\text { com cascalho, } \\
\text { litólicos e } \\
\text { Areias } \\
\text { Quartzosas. }\end{array}$ & $\begin{array}{l}\text { Áreas desmatadas e } \\
\text { queimadas recentemente, } \\
\text { solo exposto por arado/ } \\
\text { gradeação, solo exposto } \\
\text { ao longo de caminhos, } \\
\text { estradas, terraplanagens, } \\
\text { culturas de ciclo curto } \\
\text { sem práticas } \\
\text { conservacionistas. }\end{array}$ & $\begin{array}{l}\text { Situação pluviométrica com } \\
\text { distribuição regular ou não ao } \\
\text { longo do ano, com volumes } \\
\text { anuais ultrapassando } 2500 \\
\text { mm/ano; ou } \\
\text { comportamentos de chuvas } \\
\text { irregulares, com episódios de alta } \\
\text { intensidade e volumes anuais } \\
\text { baixos, geralmente abaixo de } 900 \\
\text { mm/ano. }\end{array}$ \\
\hline
\end{tabular}

* Índice de fragilidade: $\square$ 1- Muito fraco; $\square$ 2- Fraco; $\square$ 3- Médio; $\square$ 4- Forte; $\square$ 5-Muito forte.

Fonte: a) Ross (1994); b) Moroz- Caccia Gouveia (2015).

Organização: Os autores (2019). 
EM

Destarte, cabe ressaltar que na análise dos aspectos do relevo Ross (1994) recomenda a utilização dos padrões de formas semelhantes e índice de dissecação ( $3^{\circ}$ táxon) para escalas pequenas e médias, como por exemplo 1:50.000, 1:100.000, 1:250.000. No entanto, ao avaliar feições geomorfológicas associadas ao $5^{\circ}$ táxon, ou seja, em uma escala de detalhe (1:25.000, 1:10.000, etc.), sugere- se o uso das formas de vertente assim como as classes de declividade. Portanto, estas duas últimas características do relevo foram aplicadas a análise integrada da paisagem deste trabalho, considerando também os demais elementos já explicitados.

Indo de encontro com Moroz-Caccia Gouveia (2015), para o componente curvatura do relevo optou-se em atribuir os níveis de fragilidade média para as vertentes retilíneas, forte para as convexas e muito forte às côncavas. Empregamos esta classificação em função das curvaturas estarem, na área de estudo, associadas a declividade entre 6 a $20 \%$ para as retilíneas; 12 a $30 \%$ para as convexas; 20 a 30\% e acima de $30 \%$ para as côncavas.

Para analisar a Fragilidade Ambiental da bacia em estudo foi necessária a confecção de mapas de declividade, curvatura do relevo, tipos de solos e cobertura vegetal/uso da terra. Estes procedimentos foram realizados no software ArcGis 10.4 e teve como base cartográfica imagens SRTM na escala 1:150.000, na obtenção dos dados morfométricos do relevo; esboço pedológico de Presidente Prudente realizado por Fushimi (2012) para a elaboração do mapa de tipos de solos em escala de 1:25.000 e imagens do satélite Landsat TM 5 (2010), em escala de 1:100.000 concedido pela Coordenadoria de Planejamento Ambiental da Secretaria de Meio Ambiente do estado de São Paulo - SMA (2019), para a confecção cartográfica da cobertura vegetal e uso da terra. O cruzamento entre estas bases cartográficas deram origem aos mapas de Fragilidade ambiental potencial e emergente.

Uma vez realizada a confecção dos mapas sobrecitados, deu-se início a geração dos mapas de Fragilidade ambiental, por meio da análise multicriterial. Este procedimento contou com o auxílio da ferramenta Weighted overlay (sobreposição ponderada), encontrada em Actoolbox> Spatial AnalystTools> Overlay> Weighted overlay. Este método permite a atribuição de percentuais para cada variável considerada, de acordo com sua contribuição na fragilidade ambiental da paisagem estudada, de modo que a soma dos percentuais atribuídos para cada variável seja igual a $100 \%$.

Portanto, o primeiro passo foi a geração do mapa de Fragilidade do Relevo para o qual é necessário o cruzamento dos dados de declividade e curvatura do relevo, sendo concedido a cada um, nível de fragilidade ambiental de 50\%. Para a obtenção do mapa de Fragilidade Potencial foi feito o cruzamento entre os mapas de Fragilidade do relevo e tipos de solos, assim como no procedimento anterior os níveis de fragilidade atribuída a cada componente foi de 50\%. Por fim o mapa de Fragilidade Ambiental Emergente é realizado com a sobreposição ponderada dos mapas de fragilidade potencial e cobertura vegetal e uso da terra, sendo-lhes concedido os níveis de fragilidade ambiental de 50\%, respectivamente. O Quadro 2 a seguir, sintetiza o procedimento metodológico que envolve a confecção dos mapas.

Quadro 2 - Síntese da metodologia utilizada para estabelecimento da fragilidade ambiental.

\begin{tabular}{|c|c|}
\hline \multirow{2}{*}{ Etapa 1 } & Geração dos mapas base a partir de fontes pré-existentes \\
\cline { 2 - 3 } & Mapa de declividade; \\
& Mapa de curvatura do relevo; \\
Mapa de tipos de solo; \\
Mapa de cobertura vegetal e uso da terra.
\end{tabular}


EM QUESTẼO V.13 N. $03 \bullet 2020$ pág. 33-50

\begin{tabular}{|c|c|}
\hline \multirow{2}{*}{ Etapa 3 } & Geração do Mapa de Fragilidade Potencial, cruzamento dos seguintes mapas: \\
\cline { 2 - 3 } & $\begin{array}{c}\text { Mapa de Fragilidade do relevo (50\%) } \\
\text { Mapa de tipos de solo (50\%) }\end{array}$ \\
\hline \multirow{3}{*}{ Etapa 4 } & Geração do Mapa de Fragilidade Emergente, cruzamento dos seguintes mapas: \\
\cline { 2 - 2 } & $\begin{array}{c}\text { Mapa de Fragilidade Potencial (50\%) } \\
\text { Mapa de cobertura vegetal e uso da terra (50\%) }\end{array}$ \\
\hline
\end{tabular}

Fonte: a) Ross (1994); b) Moroz- Caccia Gouveia (2015).

Organização: Os autores (2019).

Os procedimentos metodológicos aqui expostos e associados a perspectiva integradora da geografia por meio de sua abordagem que leva em consideração a relação entre sociedade e natureza, possibilitaram a aquisição de resultados substanciais para a área objeto de estudo, os quais estão discriminados a seguir.

\section{Resultados e discussões}

As análises permitiram, inicialmente, a classificação dos componentes que constituem a paisagem da bacia de acordo com seu índice de fragilidade ambiental, resultando na obtenção de cinco classes: Muito Fraca, Fraca, Média, Forte e Muito forte (Quadro 3).

Quadro 3 - Síntese integrada da fragilidade ambiental na área em estudo.

\begin{tabular}{|c|c|c|c|c|}
\hline $\begin{array}{c}\text { Classes de } \\
\text { declividade }\end{array}$ & Declividade & $\begin{array}{c}\text { Curvatura } \\
\text { do relevo }\end{array}$ & Tipos de solos & $\begin{array}{c}\text { Uso da terra } \\
\text { e cobertura } \\
\text { vegetal }\end{array}$ \\
\hline Muito fraca & $0-6 \%$ & - & $\begin{array}{c}\text { Solos desenvolvidos } \\
\text { (associação de Latossolos Vermelhos) }\end{array}$ & $\begin{array}{c}\text { Cobertura } \\
\text { arbórea }\end{array}$ \\
\hline Fraca & $6-12 \%$ & - & $\begin{array}{c}\text { Solos desenvolvidos } \\
\text { (associação de Latossolos Vermelhos) }\end{array}$ & $\begin{array}{c}\text { Cobertura } \\
\text { herbácea } \\
\text { arbustiva }\end{array}$ \\
\hline Média & $12-20 \%$ & Retilínea & $\begin{array}{c}\text { Solos rasos a desenvolvidos } \\
\text { (associação de Argissolos Vermelhos) }\end{array}$ & $\begin{array}{c}\text { Solo exposto } \\
\text { Forte }\end{array}$ \\
$20-30 \%$ & Convexa & $\begin{array}{c}\text { Solos rasos } \\
\text { (associação de Neossolos Rigolíticos) }\end{array}$ & Aonstruída \\
\hline Muito forte & $>30 \%$ & Côncava & $\begin{array}{c}\text { Solos hidromórficos } \\
\text { (associação de Planossolos e } \\
\text { Gleissolos) }\end{array}$ & Água \\
\hline
\end{tabular}

Org: Os autores (2019).

Vale destacar que as superfícies onde existem os corpos d'água, bem como as suas áreas de planície de inundação, devem ser consideradas como áreas de fragilidade emergente muito forte. Essas localidades são muito frágeis, com pontos que são constantemente inundáveis em períodos com grande pluviosidade. Assim, para além dos critérios supracitados: declividade, curvatura do relevo, tipos de solo e uso da terra e cobertura vegetal, o entendimento que as áreas marginais aos canais fluviais devem ser preservadas, com presença de mata de galeria, bem como que a ocupação de suas margens se constitui como um fator de risco deve sempre ser levado em consideração, seja em áreas rurais e principalmente no espaço urbano.

A seguir, são apresentados os mapas produtos que evidenciam a fragilidade potencial e a fragilidade emergente da bacia hidrográfica do córrego da Onça. 
EM

QUESTÃO

Fragilidade Potencial

Partindo do cruzamento dos dados dos elementos naturais identificados na bacia, obteve-se o mapa de Fragilidade Potencial, como pode ser visto na Figura 7.

No mapa síntese não houve a classe Muito fraca, demonstrando o elevado índice de instabilidade natural da bacia. Cerca de $14,9 \%$ da área foi classificada em Fraco índice de fragilidade, indicando a predominância de declividades entre 0 a $12 \%$, solos desenvolvidos, concentrados principalmente nos interflúvios, solos hidromórficos nas áreas de baixa vertente e também curvatura do relevo retilíneas e côncavas. As maiores manchas de fraca instabilidade situam-se principalmente nas áreas circundantes à foz do rio da Onça, que localiza-se no extremo leste da bacia.

Figura 7 - Fragilidade Potencial da bacia hidrográfica do córrego da Onça.

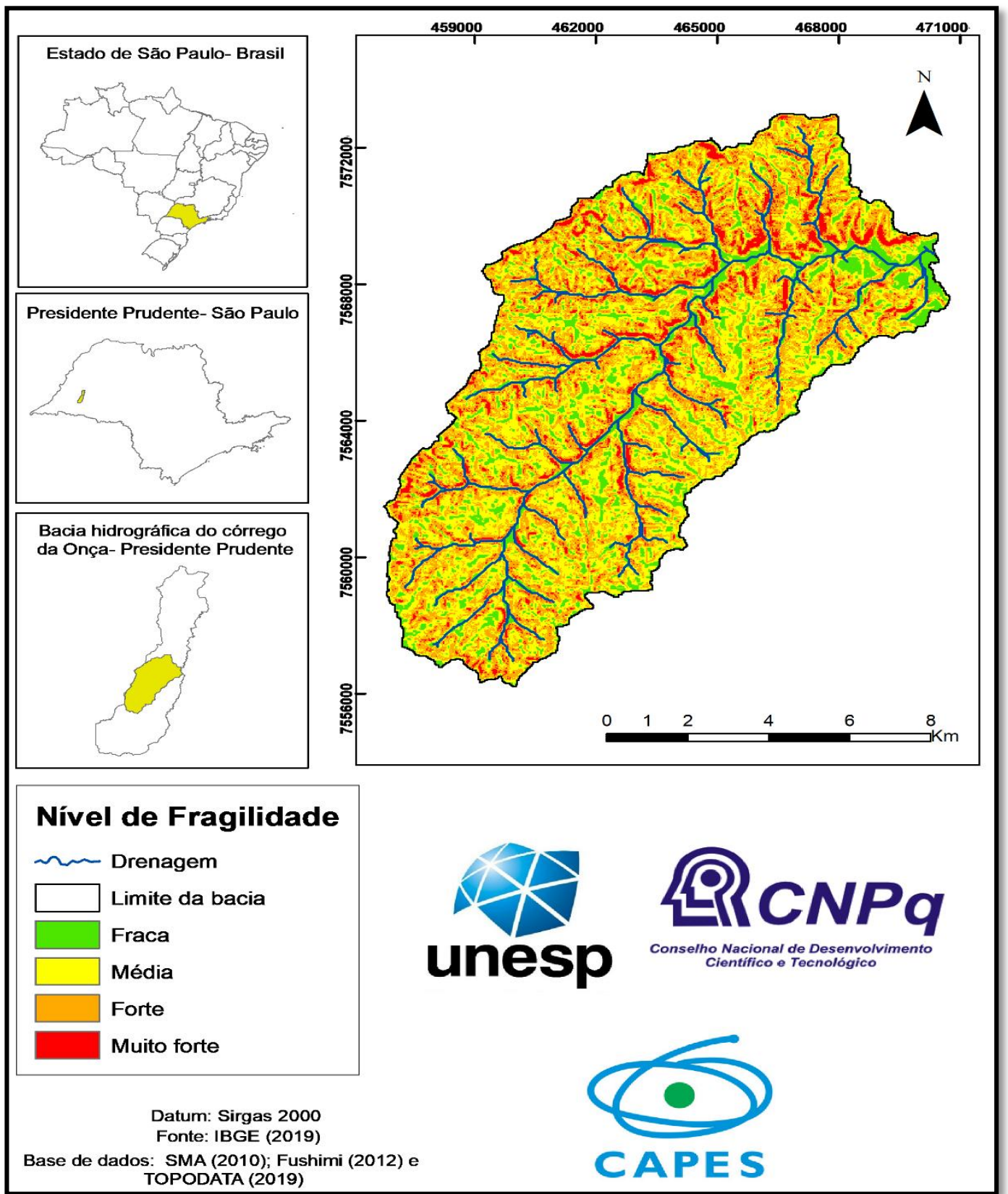

Org: Os autores (2019). 
EM

As áreas de Média fragilidade são as que abarcam a maior parte da bacia, totalizado $41,9 \%$ da mesma. Possui taxas de declividade entre 12 a 20\%, solos rasos e desenvolvidos e vertentes convexas e retilíneas. A bacia em questão também tem apresentado elevado índice de fragilidade de classe Forte, somando 33,7 \% da área. Nestes locais, há a predominância de declividades entre 20 a 30\%, solos rasos, e ainda, vertentes convexas e côncavas.

Apenas alguns pontos principalmente próximos a cabeceiras e fundo de vales apresentaram a classe de fragilidade Muito forte, correspondendo cerca de 9,5\% da área. As fragilidades muito fortes estão presentes principalmente ao longo da margem esquerda do canal principal, no setor norte da bacia hidrográfica. Nestes locais a declividade está acima de $30 \%$, os solos predominantes são os rasos e a curvatura se apresenta majoritariamente côncava. A distribuição da Fragilidade Potencial pode ser mais bem observada no gráfico 1, a seguir.

Gráfico 1 - Distribuição da Fragilidade Potencial da bacia hidrográfica em estudo.

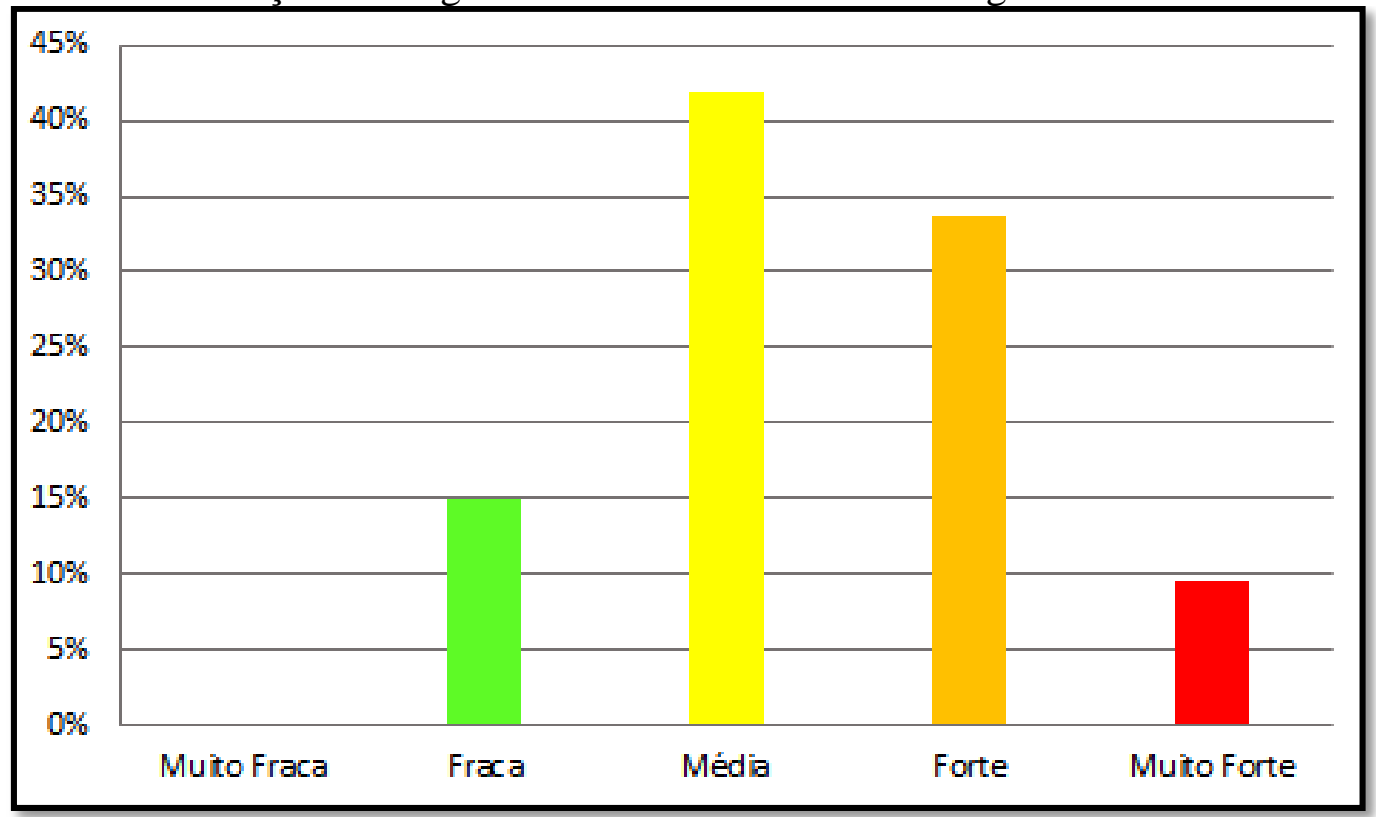

Org: Os autores (2019).

O mapa de fragilidade ambiental potencial já evidencia que em boa parte da área de estudo, faz-se necessário um modo de uso da terra que não seja facilitador da ocorrência de processos erosivos. Como exemplo as culturas temporárias, em especial aquelas dotadas de manejo pouco conservacionista e que deixem o solo exposto por vários dias do ano. O solo exposto, principalmente aqueles mais frágeis, quando submetidos a intensas precipitações favorece o incremento da erosão laminar e possibilitam o surgimento de sulcos, ravinas e até voçorocas.

Fragilidade emergente

Uma forma de incluir as atividades humanas na análise de fragilidade ambiental é a correlação junto aos dados do meio natural, o uso e cobertura da terra. Por meio do cruzamento entre essas variáveis podemos mensurar a suscetibilidade da bacia analisada diante da ação antrópica. Portanto ao analisar a Fragilidade Emergente na bacia do córrego da Onça, foi possível obter quatro classes de fragilidades (Figura 8). 
EM QUESTÃO V.13 N. $03 \downarrow 2020$

Figura 8 - Fragilidade Emergente da bacia hidrográfica do córrego da Onça.

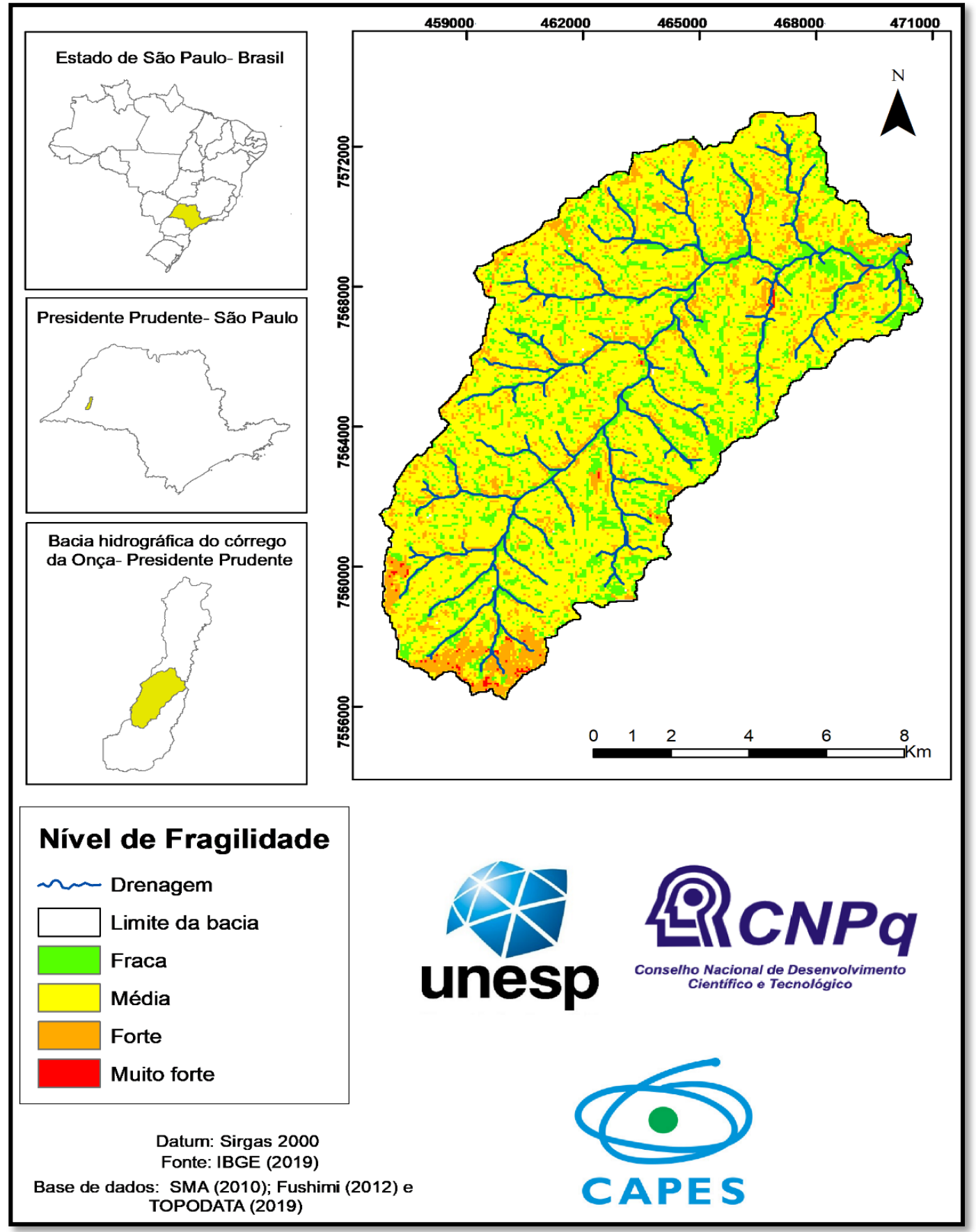

Org: Os autores (2019).

Assim como observado na Fragilidade potencial, entre as classes de Fragilidade emergente não houve a de categoria Muito fraca, o que eleva a importância de ações atinentes ao planejamento ambiental na área frente ao processo de uso e ocupação da mesma.

$\mathrm{O}$ índice Fraco de fragilidade se concentra em áreas de interflúvio, predominante no compartimento do baixo curso da bacia, somando um percentual de 4,0\%. As variáveis que caracterizam essas áreas são majoritariamente declividades entre 0 a $6 \%$, solos rasos e desenvolvidos, vertentes convexas e côncavas e uso da terra representado pela cobertura arbórea.

Todos os compartimentos da bacia apresentam grande índice de fragilidade categorizada como Média. Esta classe representa $80 \%$ de sua área total e é caracterizada por 
EM

QUESTÃO

taxas de declividade entre 6 a 20\%, solos rasos e desenvolvidos, vertentes retilíneas e convexas e cobertura herbácea arbustiva.

A classe Forte representa $15,9 \%$ da bacia e está situada principalmente em áreas urbanas, de cabeceiras e em fundos de vales. Sendo assim, os elementos que contribuem para esta classificação são declividade entre 20 a 30\%, solos rasos, vertentes convexas e côncavas e ainda uso da terra compreendido por áreas construídas e solo exposto.

Por fim a classe Muito forte compreende uma área irrisória, representando apenas $1 \%$ da bacia e está localizada em ambiente urbano e em um pequeno ponto do baixo curso. A declividade nesta classe se apresenta acima de 30\%, os solos predominantes são os hidromórficos, as vertentes são côncavas e o uso da terra se apresenta como área construída e solo exposto. A distribuição da Fragilidade Emergente pode melhor visualizada no gráfico 2, a seguir.

Gráfico 2 - Distribuição da Fragilidade Emergente da bacia hidrográfica em estudo.

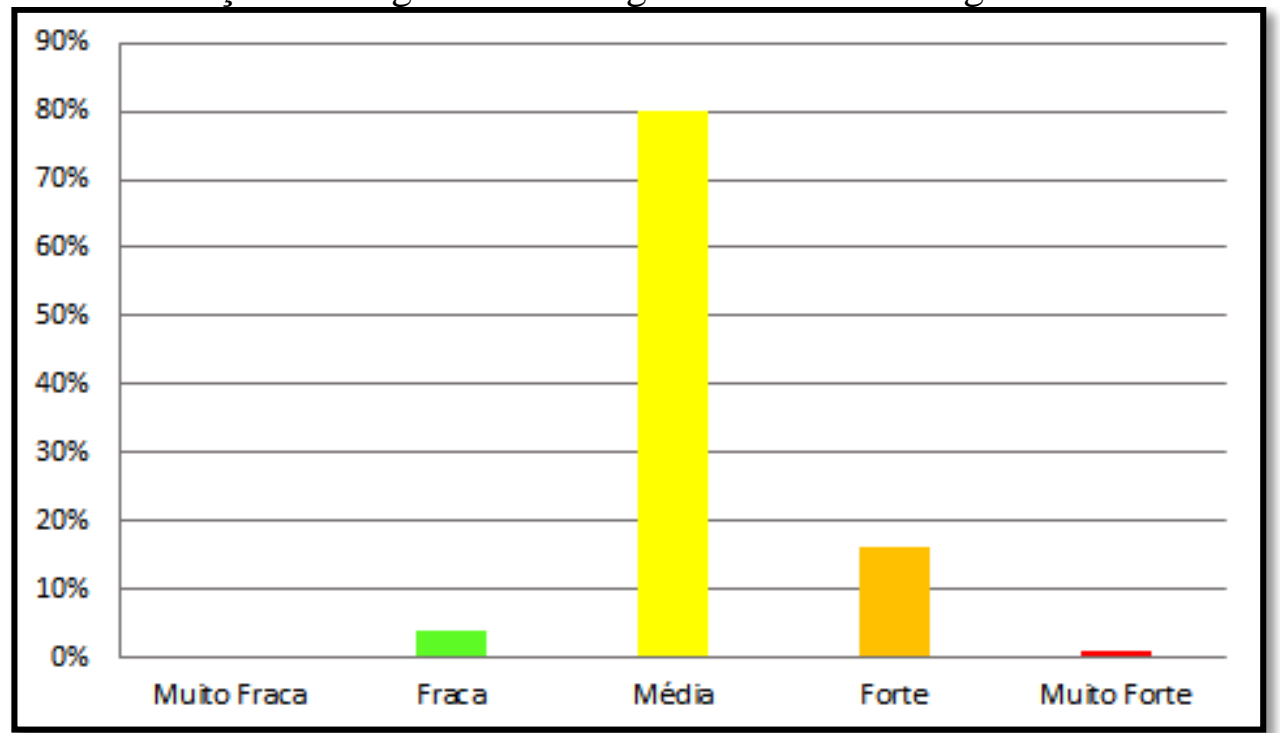

Org: Os autores (2019).

\section{Considerações finais}

Em relação a bacia hidrográfica estudada, pode-se identificar que o polígono se apresenta naturalmente instável, predominando a fragilidade potencial nível médio, seguido do índice forte, e nenhuma localidade da área de estudo possui uma fragilidade muito fraca, ou seja, os locais mais frágeis se situam principalmente em pontos que apresentam solos mais susceptíveis à erosão e declividades mais acentuadas. São, portanto, estes pontos/lugares que o/os órgão(s) gestor(es) do território deve dar uma atenção especial e pensar em políticas de uso menos degradante e mais conservacionista.

Se o relevo e os tipos de solos foram apresentados como elementos de maior contribuição para a instabilidade ambiental potencial da paisagem na bacia do córrego da Onça, pode se destacar que a concentração do índice Médio da Fragilidade emergente em mais da metade da bacia está associada ao seu baixo adensamento populacional e a presença de cobertura arbórea em áreas de cabeceiras e fundo de vales. Tais fatores tem se mostrado como atenuantes de processos degenerativos mais críticos, e o avanço das classes forte e muito forte. 
EM

Todavia, nota- se a importância do planejamento ambiental que vá além das áreas urbanas, visto que esta compreende uma ínfima área da bacia, sendo o espaço rural o mais representativo. Este por sua vez é dominado pelo uso de culturas agrícolas temporárias as quais, quando não possuem um manejo adequado, podem impactar diretamente seus corpos hídricos, inerentes principalmente, a processos de erosão acelerada. Outro fator importante a ser considerado é que apesar da área urbana ser pouco representativa, o crescimento populacional junto à expansão da malha urbana da cidade de Presidente Prudente pode ocorrer nesta área. Isso demandaria uma criteriosa forma de expansão urbana, dado as características instáveis da bacia.

Destarte, o uso desta metodologia não só pelos pesquisadores, mas também pelos órgãos gestores do território é uma importante ferramenta para o ordenamento e o planejamento ambiental, seja na micro, meso, ou macro escala, contribuindo para um uso menos degradante do meio físico e estabelecendo uma relação sociedade-natureza que vá além da forma intensiva que se dá a todo momento pela lógica de mercado.

\section{Referências}

AMARAL, R.; ROSS, J.L.S. As Unidades Ecodinâmicas na análise da fragilidade ambiental do Parque Estadual do Morro do Diabo e entorno Teodoro Sampaio - SP. GEOUSP - Espaço e Tempo, São Paulo, No 26, p. 59 - 78, 2009.

BERTALANFFY, L. V. The theory of open systems in physics and biology. Science. Washington, v. 111, p. 23- 29, 1950.

Teoria Geral dos Sistemas. Tradução de Francisco M. Guimarães. Petrópolis: Vozes, 1973.

BERTRAND, G. Paysage et geographie physique globale: esquisse méthodologique. Rev. Géograph. Pyrénées et du Sud-Ouest, 39(3):249-272, Toulouse, 1968.

BOIN, M.N. Chuvas e Erosões no Oeste Paulista: Uma Análise Climatológica Aplicada. Tese (Doutorado em Geociências e Meio Ambiente). Rio Claro: UNESP. 264p. 2000.

BOTELHO, R.G.M. Planejamento Ambiental em Microbacia Hidrográfica: in GUERRA, A.J.T.; SILVA,A.S. da \& BOTELHO, R.G.M.(2005) Erosão e Conservação dos Solos, Bertrand Brasil, Rio de Janeiro, 340p. 2005.

CENDRERO, A. Técnicas e instrumentos de análisis para Ia evaluación, planificación y gestión dei médio ambiente. Serie opiniones, n 6. CIFCA. Madri, 1-67, 1982.

EMPRESA BRASILEIRA DE PESQUISA AGROPECUÁRIA - EMBRAPA. Sistema brasileiro de classificação de solos. 3 ed. Brasília, 2013. 353p.

FUSHIMI, M; NUNES, J.O.R. Principais Classes de Solos do Município de Presidente Prudente-SP: identificação e caracterização. Boletim Goiano de Geografia, Goiânia, v.32, n.1, p. 45-58, jan/jun 2012. 
EM

FUSHIMI, M. Vulnerabilidade ambiental aos processos erosivos lineares nas áreas rurais do município de Presidente Prudente - SP. 2012. 141f. Dissertação (Mestrado em Geografia) - Faculdade de Ciências e Tecnologia, Universidade Estadual Paulista, Presidente Prudente.

GALLOPIN, G. El ambiente humano y planificación ambientai Madri. Centro Internacional de Formación en Ciências dei Ambiente (Opiniones, Fascículos de Médio Ambiente n9 1), 1981, 30p.

GODOY, M. C. T. F. Estudo hidrogeológico das zonas não saturada e saturada da formação Adamantina, em Presidente Prudente, Estado de São Paulo. 1999. 156f. Tese (doutorado em recursos minerais e hidrogeologia) - Universidade de São Paulo, Instituto de Geociências, São Paulo.

HACK, J. T. "Interpretation of erosional topography in humid temperate regions". American Journal of Science. Bradley, v. 258, p. 80-97, 1960.

HAYDEN, R.S. Geomorphological mapping. In: SHORT, N. M.; BLAIR Jr., R.W. Geomorphology from space. Washington, DC, NASA, p. 637-640, 1986.

INPE - INSTITUTO NACIONAL DE PESQUISAS ESPACIAIS. Banco de Dados Geomorfométricos do Brasil. Topodata. s.d. Disponível em: < http://www.dsr.inpe.br/topodata/dados.php>. Acesso em: 10/04/2019.

INSTITUTO BRASILEIRO DE GEOGRAFIA E ESTATÍSTICA (IBGE). Geociências. Disponível em: <https://downloads.ibge.gov.br/downloads_geociencias.htm>. Acesso em: 20/05/2019.

LOMBARDI NETO, F.; MOLDENHAUER, W.C. Erosividade da chuva: sua distribuição e relação com as perdas de solo em Campinas (SP). Bragantia, Campinas, 51(2):189-196, 1992.

MONTEIRO CAF. 1973. A dinâmica climática e as chuvas do estado de São Paulo: estudo geográfico sob forma de atlas. São Paulo: USP. 130p.

MOROZ-CACCIA GOUVEIA, I. C. Tutorial - Mapa de Fragilidade Ambiental no Arcgis. Material didático laborado para a disciplina de Pós-Graduação "Geomorfologia Aplicada ao Planejamento Ambiental, FCT-UNESP, Presidente Prudente, 2015.

MOROZ-CACCIA GOUVEIA, I. C.; GOUVEIA, J. M. C.; PIMENTA, J. P. de O. Fragilidade Ambiental aos processos erosivos lineares no Pontal do Paranapanema. In: XVI Encontro de Geógrafos da América Latina. 2017. Anais... Bolívia. Disponível em: < http://observatoriogeograficoamericalatina.org.mx/egal16/Nuevastecnologias/Sig/06.pdf>. Acesso em 10/04/2019.

NUNES, J. O. R.; FREIRE, R.; PEREZ, I. U. Mapeamento Geomorfológico do perímetro urbano do município de Presidente Prudente-SP. In: VI Simpósio Nacional de Geomorfologia; I.A.G. Regional Conference on Geomorfology, 2006, Goiânia. Anais... 
EM

QUESTÃO V.13 N. $03 \bullet 2020$

pág. 33-50

Goiânia: União da Geomorfologia Brasileira; International Association of Geomorphologists, 2006.

et. al. Contribuição ao conhecimento geomorfológico para as análises em SIG: seleção de áreas para construção de aterro sanitário - Presidente Prudente - SP - Brasil. In: NUNES, J. O. R. e ROCHA, P. C (org.). Geomorfologia: aplicação e metodologias. $1^{\circ} \mathrm{ed}$. São Paulo: Expressão Popular: UNESP. Programa de pós-graduação em Geografia, 2008.

ROSS, J. L. S. Geomorfologia, Ambiente e Planejamento, Editora Contexto, São Paulo. 1990. 85p.

Análise empírica da fragilidade dos ambientes naturais e antropizados. Revista do Departamento de Geografia. nº.8. FFLCH-USP: São Paulo. 1994.

Análise empírica da fragilidade dos ambientes naturais e antropizados. Revista do Departamento de Geografia $n^{\circ} .8$. FFLCH-USP: São Paulo. ROSS, J. E.; Total quality management. Florida: 2 Ed., St. Lucie Press, 1995.

; MOROZ, I. C. Mapa geomorfológico do Estado de São Paulo. Rev. do Departamento de Geografia (USP), São Paulo, n. 10, 1996.

SOTCHAVA, V.B. O estudo de Geossistemas. Métodos em questão. 16. IG-USP. São Paulo, p. 1-52, 1977.

SÃO PAUlO, Mapeamento de Cobertura da Terra do Estado de São Paulo - 2010escala 1:100.000 - Coordenadoria de Planejamento Ambiental, Secretaria do Meio Ambiente do Estado de São Paulo, 2013

STRAHLER, A.N. Dynamic basis of Geomorphology. Geol.Sol. American Bulletin, 63, pp.923-938, 1952.

SPÖRL, C. Análise da fragilidade ambiental relevo-solo com aplicação de três modelos alternativos nas altas bacias do Rio Jaguari Mirim, Ribeirão do Quartel e Ribeirão da Prata. São Paulo, 1v. Dissertação (Mestrado) - Faculdade de Filosofia, Letras e Ciências Humanas, Universidade de São Paulo, São Paulo, 2001.

SPÖRL, C.; ROSS, J.L.S. Análise comparativa da fragilidade ambiental com aplicação de três modelos. Geousp - Espaço e Tempo. p. 39-49, 2004.

TRICART, J. Mise au point - L'évolution des versants. L'information geographique, 1956.

Ecodinâmica. Rio de Janeiro: FIBGE, Secretaria de planejamento da Presidência da República, 1977.

TROPPMAIR, H. \& GALINA, M. H. Geossitema in Mercator. Revista de Geografia da UFC, ano 05, número 10, Fortaleza, 2006. 